\title{
Yazının Dijital Ortamda Rezonansı ve İçeriğin Yüzeyselleşmesi
}

\author{
Rıdvan Yücel (Öğr. Gör. Dr.) \\ Akdeniz Üniversitesi İletişim Fakültesi \\ ridvanyucel@akdeniz.edu.tr \\ ORCID: 0000-0001-8976-7213
}

Başvuru Tarihi: 01.08.2019

Yayına Kabul Tarihi: 21.10.2019

Yayınlanma Tarihi: 24.01.2020

DOI: http://10.17680/erciyesiletisim.600256

\section{Öz}

Tarih boyunca iletişim araçlarının teknolojisine bağlı olarak iletişim unsurlarının niteliğinde değişimler gerçekleşmiştir. Günümüzde de iletişim ortamı bilgisayar ve internet sayesinde değişmektedir. İnsanlık tarihinin önemli iletişim unsurlarından birisi olan yazı bu süreçte hem nitelik hem de nicelik olarak değişime uğramaktadır. Bilgisayar ve internet içeriğin üretimini ve tüketimini hızlandırmış, bu sayede yazının içeriği seyrelmiş, bilginin ağırlığı azalmıştır. Yazının okunduğu ortamlar ve multimedya teknolojisi yazının anlatım gücünü azaltmıștır. Reklam ve okunma kaygısı ile okuyucuların entelektüel seviyelerini zorlamayan içerikler üretilmeye başlanmıştır. İnternetteki yoğunlukta fark edilme kaygısı yaşayan ve ön plana çıkmaya çalışan içerik üreticileri yazıyı video, grafik gibi diğer iletişim unsurlarıyla birlikte sunarak okuyucunun dikkatini birden fazla parçaya yöneltmeye başlamışlardır. Yeni iletişim teknolojileriyle birlikte yazının kolayca üretilip yayılması, yayın maliyetinin düşmesi yazının yayın sürecine hazırlanırken harcanan emeğin ve kalite sorunun ortaya çıkmasını beraberinde getirmiştir. Yazı, dijital iletişim araçlarının ağırlıkta olduğu günümüzde yeni bir form ve içerik kazanmış gözükmektedir. Bu çalışmada yazının içerisinde bulunduğu ortama göre belirli imkanlara, sınırlara göre şekil aldığı varsayılmıştır. Yazının imkan ve sınırları yazının söylemini biçimlendirmiştir. Bu bağlamda, bu çalıșmada yazının ortamlara göre değișen özelliklerini ortaya koymak amaçlanmıştır. Yazının değişen söylemi, yazılı ve dijital ortamlardaki özellikleri literatür taraması yapılarak ve konu hakkında temel ve güncel eserler incelenerek ortaya konmaya çalışılmıştır.

Anahtar Kelimeler: Okuma, Yazılı kültür, Dijital kültür, Rezonans, Yüzeyselleşme. 


\title{
Digital Resonance of Writing and Becoming Superficial of the Content
}

\author{
Rıdvan Yücel (Lect. Ph.D.) \\ Akdeniz University Faculty of Communication \\ ridvanyucel@akdeniz.edu.tr \\ ORCID: 0000-0001-8976-7213
}

Date Received: 01.08.2019

Date Accepted: 21.10.2019

Date Published: 24.01.2020

DOI: http://10.17680/erciyesiletisim.600256

\begin{abstract}
The quality of communication factors has gone through changes throughout history due to the changes in technologies of means of communications. Communication is still changing today thanks to computers and Internet. Writing as the most important communication component of history of humanity is going through both qualitative and quantitative changes. Computers and Internet have speeded up the production and consumption processes of the content, and thus the content of writing became thinner while density of knowledge is reduced. The environments in which writing is read and multimedia technologies have caused reduction in the power of expression. Advertisements and the concern to be read led to the production of content which does not push the intellectual limits of readers. Concerned with being seen and wanting to stand out in the crowd, content generators were led to direct the reader's attention to many factors apart from writing using other communication tools such as video, graphics etc. The ease in generation and distribution of writing and the reduction in publishing costs with new communication technologies brought with them the issues of labor and quality in the process of preparing texts for publication. Writing looks like it had acquired a new form and content today with the dominance of digital communication tools. In this study, it is assumed that the writing forms according to the medium and certain opportunities and limits. The opportunities and limits of the writing form the discourse of the writing. In this context, in this study, it is aimed to reveal the characteristics of writing that change according to the media. The changing discourse of writing and its features in written and digital media have been tried to be revealed by literature review and by examining the basic and current works on the subject.
\end{abstract}

Keywords: Reading, Written culture, Digital culture, Resonance, Superficiality. 


\section{Giriş}

Teknoloji büyük bir hızla ilerlemekte ve insan hayatında değişimler meydana getirmektedir. Değişim bazen farkedilirken bazen de farkında olunamayacak kadar geniş zamana yayılmaktadır. Bu noktada gözden kaçan unsurlardan birisi yazının taşındığı, içinde bulunduğu ortama göre niteliğinde değişimlerin meydana gelmesidir. Esasen teknolojinin kültür üzerindeki belirlenimciliği pek çok akademisyen, araştırmacı ve filozof tarafından işlenmiş, iletişim araçlarının mesaj ile ilişkisine dikkat çekilmiştir. Bu bağlamda Walter Ong (2007), Barry Sanders (2012), Neil Postman (2012), Marshall McLuhan (2001), Manuel Castells (2016), Jan Van Dijk (2018) yaptıkları çalışmalarla bilinen isimlerdir. Ancak son zamanlarda internetin doğurduğu baskın kültür ve "üst araç" haline gelmesi pek çok içeriği ve içerik sunumunu tümden değiştirdiği ve bu durumda yeni araştırma alanları açtığı söylenebilir. Yeni teknoloji kullanımı ile gelen değişimin oluşturduğu alana dair pek çok araştırma yapılmaktadır. Ancak halen yeni sorular sormak ve cevaplar aramak gerekmektedir.

Dolayısıyla bu çalışma kapsamında yazılı veya tipografik içeriğin basılı veya dijital olmak üzere sunulduğu ortama göre rezonans yaparak niteliğinin erozyona uğraması; ortamlara göre içeriğin niteliğinin nasıl değiştiği; içeriğin yüzeyselleşmesinin zihinsel süreçler bakımından içerdiği sonuçların neler olduğu; bu süreçte insanlardan ne talep edildiği gibi sorulara yanıt aranmaktadır.

İnsanlık tarihi boyunca kullanılan her bir iletişim teknolojisi insanın doğuştan getirdiği iletişimsel özelliklerini pekiştirmiş, genișletmiş ve değiștirmiştir. Her bir iletişim aracı farklı dönemlerde ön plana çıkmış, insanın iletişim yeteneklerinin karakteristik özelliklerinin tanımlanmasında etkide bulunmuştur. Bu bağlamda gerek insanlar olarak içinde yaşanılan toplumda kurulan ilişkilerin biçimsel özellikleri gerekse de bireysel düzlemdeki bilişsel yapılar egemen olan iletişim araçlarının özellikleriyle sıkı bir ilişki içindedir. Sözlü, yazılı ve dijital kültürler, ayrı ayrı insanın belirli özelliklerini ve duyumunu daha fazla meşgul ederek insanı ve dolayısıyla toplumu etkiler. İnsana, özellikle algısal boyutunda belirli bir eğilim kazandırır. Eğilim nihayetinde bütün toplum üzerinde kendisini gösterir ve uzun vadede toplumu belirlemez ancak siyaset, kültür, ekonomi, sanat, mimari, bilim, din gibi alanlarda kendisini göstererek yavaş ama karşı konulamaz değişimler yaşanmasını sağlar (Rowland, 2014, s. 10).

\footnotetext{
"Her medyum, araç (ortam) özgül ve karmaşık bir tarihsel özelliğe sahiptir ve aracın tarihselliği, sadece bir teknolojinin bir diğerini nasıl izlediğinin veyahut onun yerini aldığının ya da mucitlerin yarattığı birtakım teknolojilerin dünya üzerindeki sihirli etkisinin öykülerinden oluşmaz, tam tersine, toplumsallığından ve kültürelliğinden kaynaklanır" (Gitelman, 2006, s.7).
}

Postman, dilde kullanılan bütün yapıları anlamın kendisi değil ama anlamın aktarılmasında kullanılan araçlar olduğu için mecaz olarak değerlendirir. İnsanın mecaz kullanması, sembolik anlamlar üretmesi zaman içerisinde onun bilincinin bir parçası olmuştur ve mecaz kullanımı iletişim sürecinde güçlü bir konuma yükselmiştir. Özel bir dikkat sağlanmadıkça bilincin bu becerisi fark edilemez. "İnsan dilsel biçimler, sanatsal imgeler, mitsel semboller ya da dinsel ayinlerle kendi etrafına öyle bir zar örmüştür ki, yapay (bir) aracın dolayımı olmadan hiçbir şey göremez ya da bilemez" (Postman, 2012, s. 19). Mecazın sözle, yazıyla, görüntüyle ya da farklı unsurların aynı anda kullanılmasıyla aktarım kabiliyeti, derinliği, insanın düşünsel kabiliyeti değişim göstermektedir. 
Yazı bir iletişim unsuru olarak mağara duvarlarına çizilen resimlere dayanmaktadır. Ancak yazının, Sümerler'in hesaplamalar ve muhasebe kayıtları için kullandıkları kil tabletlerle birlikte ortaya çıktığı kabul edilmektedir. Bununla birlikte yazılı, basılı ya da tipografik kültür ifadeleri ile kast edilen fonetik alfabenin doğuşuyla başlayan, kodeksin kullanımı ile gelișen, matbaanın icadıyla tam olarak kendisini bulan kültür ortamının ifadesidir (Robinson, 2014, s. 69). Yazı ve matbaanın buluşması gazetelerin ortaya çıkmasını beraberinde getirmiştir. Daha sonra telgrafın sürece eklemlenmesi gazetenin etkisini pekiştirmiş, sunulan enformasyon miktarında büyük bir artışa neden olmuştur. Bu belki de insanın yaşadığı çevrenin dışında günlük olarak enformasyon almaya başlayarak zihinsel bir kopma yaşamasının ilk adımı olmuştur. Enformasyonun bağlamı genişlemiş, bu duruma sosyal, kültürel ve tabii ekonomik ve politik süreçler eşlik etmiştir. Daha sonrasında radyo ve televizyonun kitle medyası olarak ortaya çıkması iletişimi yeni bağlamlara taşımıştır. Söz konusu bütün medyalar kendi metaforlarını üretmiş, kendilerine has duyumsama oluşturmuş geleneksel olarak nitelendirilen iletişim ortamlarıdır. Dijital ortamlar ise geleneksel ortamlardan farklı olarak ikilik sayı tabanına dayanan interneti ve internet temelli iletişim ortamlarını ifade etmektedir. "Bilgi ve iletişim teknolojileri ve bunlarla bağlantılı sosyal bağlamları, iletişim becerilerini arttıran cihazları, bu cihazları kullanarak geliştirilen iletişim etkinlikleri ile pratiklerini ve bu cihazlarla pratikler etrafında şekillenen sosyal düzenleme veya örgütlenmeleri kapsamaktadır" (Binark, 2014, s. 15).

Bir içerik mevcut ortamından koparılıp başka bir ortama taşındığında rezonans yapar ve yeni bağlamlara bürünür. "Yeni bir araç (medium), söylem yapısını, aklın kullanılışının bazı yollarını cesaretlendirerek, belli zeka ve bilgelik tanımlarını öne çıkararak ve belli türde bir içerik talep ederek (özel bir deyişle, hakikati öğrenmenin yeni biçimlerini yaratarak) değiştirir" (Postman, 2012, s. 37). Dijital ortamlara taşınarak farklı içeriklerle ve kaliteyle karşımıza çıkan yazı, bizi kendisi hakkında yeniden düşünmeye mecbur etmektedir. "Okuma-yazma kuramı alanında hiçbir şey, farkında olmanın farkındalığının, düşünme hakkında düşünmenin, yorumlarımızı yorumlamanın rolüne bakmak ve yeniden bakmaktan daha önemli değildir" (Berthof, 1998, s. 17). Bu çalışma kapsamında dijital ortamda rezonans yapan yazınsal metaforun, içerik kalitesinin değişime uğraması ana odak noktalardan birisi olacaktır.

Çalışma yazının basılı ve dijital ortamlardaki nitelikleri üzerine odaklanılarak hazırlanmıştır. Dolaysıyla çalışmanın kapsamı ve sınırlarını yazılı metnin basılı ortamdan dijital ortama geçerken yaşadığı değişim oluşturmaktadır. Çalışmada ilk olarak, yazı ile insanın buluşması olan "okuma”nın ne olduğu sorusuna cevap aranmıştır. Ardından içeriğe yön veren unsurlar olarak basılı ve dijital ortamların nitelikleri irdelenmeye çalışılmış; yazılı içeriğin basılı ya da dijital ortamlarda bulunmasına göre değișen özellikleri ortaya konmuştur. Son olarak dijital ve basılı ortamlardaki içeriğin şekillendirdiği bilinç özelliklerinin, ne tür bir düşünme yetisini geliștirdikleri aktarılmıștır. Bu kıyaslamaları yapmak suretiyle dijital ortamların içeriğe etkisine erişilmeye çalışmış, bu amacın izi sürülmüștür.

Çalışmada basılı ortamlarda yer alan yazıların özellikleri ile dijital ortamda yer alan yazıların özellikleri literatür çalışması yapılarak, alandaki temel ve güncel çalışmaların incelenmesi ile ortaya konmuştur. Bununla birlikte çalışmada yazının ele alınması temel olarak betimsel analiz tekniği ile gerçekleşmiştir. Ortamların içerik üzerindeki belirleyiciliğinden hareketle, bulunduğu ortama göre șekil almakta olan yazının ne tür özellikler ortaya koyduğu incelenmiştir. Nitekim ortam, insanı daha hızlı bir yazı 
tüketimine ve dolayısıyla hızlı ama yüzeysel biçimde düşünmeye, kavrayışa iteceği gibi; yine ortamın bir getirisi olarak, yazıyla geçirilen uzun zaman neticesinde yazının insan zihninde daha kalıcı hale gelmesine etki eden genel ve soyut ifade imkanları ortaya çıkabilmektedir. Bu haliyle ortamın kendisi mesaja sinmekte, mesajın rengine, kokusuna etki etmektedir.

\section{Okuma Nedir?}

"Okumak" yazı ya da fonetik alfabe ile sınırlı olan bir beceri değildir. Dahası, okuma becerisi insanlar yazıyı icat etmeden evvel, doğaya bakarak, belli örüntüleri çözümleyerek geliştirilmişti. Yazı okumak, şekillerin ifade ettiği sesleri ya da anlamları çözmenin basit bir biçimidir. Ancak okuryazarlık okumadan daha fazlasını gerektirir. Yazıyı okumak veya yazıyı sökmek sınırlı bir iştir ancak okuryazar olmak, derinlemesine okumak yazı gerektirmeden de yapılabilen ve sonu olmayan derin bir iştir. Bu bağlamda okuryazarlık veya derinlemesine okuma yapmak aslında örüntü tanıma işidir.

\footnotetext{
"Bir sayfanın üzerinde yazılı olduğu harfleri okumak onun girdiği kılıklardan yalnızca bir tanesi. Artık var olmayan yıldızların haritasını okuyan bir gök bilimci; bir evin yaplacağı yeri kötü ruhlara karşı korumak için 'okuyan' Japon mimar; ormanda hayvanların izlerini okuyan zoolog; kazanacak kağıdı oynamadan evvel ortağının hareketlerini 'okuyan' kağıt oyuncusu; koreografın notlarını 'okuyan' dansçı ve dansçının sahnedeki hareketlerini 'okuyan' izleyici; örülmekte olan bir halının karmaşık desenlerini "okuyan" dokumacı; sayfanın üstünde birleștirilmiş birden çok nota dizinini 'okuyan' org sanatçısı; bebeğin yüzünde neşe, şaşkınlık ya da korkunun belirtilerini 'okuyan' ana baba; bir kaplumbağa kabuğundaki eski izleri 'okuyan' Çinli falcı; gecenin içinde ve çarşafların altında, sevgilinin bedenini görmeden 'okuyan' aşık; hastalarına kendi akıl almaz rüyalarını 'okumaya' yardım eden psikolog; elini suya daldırıp da okyanusun akıntılarını 'okuyan' Hawaii'li balıkçı; gökyüzünde hava durumunu 'okuyan' çiftçi: Hepsi işaretleri çözebilme ve anlaşılır kılma eylemini kitap okurları ile paylaşıyorlar" (Manguel, 2013, s. 19).
}

Okumak yorumlamaktır; yorumlamak ise gerçekliği insanın kendisine, kendi algı düzeyine, yaşamına, meşrebine göre uyumlandırmasıdır. Bu çerçeveden baktığımızda okumak bizim kaçınılmaz olarak yaptığımız hayatı, dünyayı, kendimizi anlama eylemidir. $\mathrm{Bu}$ anlamda metinde uykuda olan bütün anlam ihtimallerinden okurun tercih edeceği bir tanesi, okurun anlama çabası tarafından uyandırılır ve okurun yeğlediği bir anlamın kendisine giydirilmesi ile dolaşıma sokulur. Giydirilen anlamı her ne kadar okur seçmişse de anlam yazarın maksadından çok uzakta değildir. İnsanın anlam arayışı kendi varlığına içkin bir tavırdır ve kaybolmaz. Okuma bu tavrın bir gereği olarak ortaya çıkmakta, ontolojik olarak kaçınılmaz bir gerekliliğe cevap vermektedir.

\footnotetext{
"Okumayı ve yazmayı öğrenme eylemi; insanoğlunun sözcükleri okumadan önce yaptığı bir şey olan, dünyayı okuma eylemine ilişkin çok kapsamlı bir anlayıștan yola çıkmak zorundadır. Tarihsel olarak da insanoğulları da önce dünyayı değiştirdiler, arkasından dünyayı açıkça ilan ettiler ve sonra sözcükleri yazdılar" (Berthof, 1998, s. 20).
}

Yazı, yazan tarafından kodlanmakta; anlam yazar tarafında yazının içinde inşa edilmekte; ifade yazarın dilsel kabiliyetinden geçmektedir. Ancak "okuma" eylemi okur tarafından gerçekleştirilir ve okurun zihinsel kodları, yapısı, yönelimi veya tutumu yazının anlaşılmasında, kodun çözümlenmesinde çok önemlidir. Nesneler, olaylar arasında, bir düzeni fark etme sorumluluğu okura aittir ve okurun gayreti olmaksızın anlamın ortaya çıkması mümkün değildir. İnsanlar tarih boyunca evrendeki yerini anlamak için, hayatta kalmak için, refah içinde olmak ve erdemli bir yaşam için çevrelerini okumuşlardır.

Okurun gücünün bir diğer göstergesi de kutsal kitaplar üzerine yapılan okumalar sonrasında çıkan farklı yorumlar ve ekollerdir (Paine, 2018). Metnin sabit olduğu, 
yüzyıllardır değişmediği kitapların takipçilerinin kitaplardan çıkardıkları sonuçlar ve bu kesimler arasındaki oluşan farklılıklar söz konusudur. Bir metin üzerinde okuma arttıkça o metinden çıkarılan anlamların çeşitlenmesi artmaktadır. Bu bağlamda okumak hermeneutik bir eylemdir. Yazıyı salt harflerden oluşan bir kodlama olarak görmeyip yazıda söylenenin ötesine geçmeye, başka metinlerle bir araya getirerek olası anlam ihtimallerini değerlendirerek doğru anlama erişmeye çalışmaktır.

Okumak için belirli örüntüleri bir araya getirecek parçaları gözlemleyebilmiş olmak, bu işi yapacak kadar süre boyunca izlemede kalmış olmak gerekir. Bu eylem zamanda yapılan, zaman ile yapılan bir eylemdir. Okuma eylemi bu haliyle zamanı belli aralıklarla kavramaktan geçmektedir. İzlenen zaman aralıklarında gerçekleşen eylemlerin birbirleriyle kurulan doğru korelasyonu daha geniş bir zaman veya düzenin habercisidir. $\mathrm{Bu}$ izlekler zaman üzerinde takip edilen işaretlerin bir yolun sonucu olduğundan okuma eylemi gelişkin toplumların zamansal algıları da gelişmiştir. Okuryazar toplumların kuvvetli bir geçmiş, şimdiki ve gelecek zaman algıları vardır. Sonsuz bir şimdinin kıskacından zihinlerini kurtarmıș, geçmişi tecrübe ve bilgi boyutuna getirerek özümsemişlerdir (Goody, 2011). Yazı anlam kaybını en aza indirerek, okuyanın tahayyülünü kendisiyle aktarılana ekleyerek katmanlar oluşturmakta, anlam zenginliği için alan ve imkan sağlamaktadır. Paolo Freire'ye göre de yazı sadece sözlü olanın kodu değil; yaşanan dünyaya ilişkin bilgiyi içeren ama onun önünde giden ve onunla iç içe geçmiş bilgidir (1998, s. 72-77).

Yazının yazılma aşaması bittikten sonra, okunurken, okur tarafından yeniden yazılır. $\mathrm{Bu}$ nihai yazım yazarın da kaderidir. Çünkü anlaşılamadı̆̆ında sayfalarda kalacaktır ve zihinde tekrar canlanmayacaktır. Ayrıca nihai yazım yazarın yaşayacağı zamanı ve coğrafyayı da belirlemektedir. Kitabı yazdıktan yüz yıl sonra okunmaya başlanan yazarlar vardır; yazar kitabını yazdığı yerde değil okunduğu yerde yaşar. Ezequel Martinez Estrada, "Kimileri vardır ki, okurken anımsar, karşılaştırır, başka ve daha önceki okumalardan duygular çıkarıp getiriverirler." (Manguel, 2013, s. 34). Metin kişiye özel açılımlar verir. Aynı metin farklı kimselerce farklı algılanır. Bu durumda okuma yazıları çözme işi değil yorumlama işidir. Yorumlamaya dünya bilgisi eşlik eder. Bu bilgi ne kadar geniş ve derin olursa yapilacak olan okumalardan elde edilen en fazla miktarda ve doğru biçimde sağlanmış olur. "Kısa sürede okumanın kümülatif olduğunu ve geometrik olarak arttığını öğrendim: Her yeni okuma, okurun daha önce okuduklarının üstüne ekleniyordu" (Manguel, 2013, s. 34).

Kitaplar matbaa icat edilmeden evvel yazıcılar tarafından elle yazılmışlardır. Genellikle kilise çatısı altında, uzun ve zahmetli bir çalışma ile kitaplar çoğaltılmıştır. Okuma bile kişi sayısı da son derece azdır ve okuma genellikle kalabalık kitleler karşısında yapılmıştır. "Söz uçar yazı kalır" sözü, kitap sayfasında cansız duran sözcüklere ses ile can verilerek, kalabalıkların zihinlerinde canlanmasını ifade etmek, "sözcügü kanatlandırmak" anlamında kullanılmıştır (Manguel, 2013, s. 64). Zamanla kitap sayıları artmış, okuma yaygınlaşmış ve bireysel bir eylem haline gelmiştir. Yazının ilk örneğinin muhasebe amaçlı Sümer tabletleri olduğu, "auditing" kelimesinin hem muhasebe hem de yüksek sesle okumak anlamına geldiği ve yakın zamana kadar muhasebe kayıtlarının denetçilere yüksek sesle okunmak kaydıyla yapıldığını hatırlamak gerekmektedir (Ong, 2007, s. 142). Dolaysıyla materyalin [iletişim ortamının] kendisi değiştikçe, yaygınlaştıkça, kullanımı sıklaştıkça materyal [iletişim ortamı] üzerinden yapılan davranışlar da değişmektedir. Değişen kullanımlar farklı türlerde içerik, düşünsel kabiliyeti de beraberinde getirmektedir. 
Okuma üzerine pek çok benzetme yapılmıştır. Okuma eylemi hem yapılan bu eğretilemeler hem de insanın sinir sistemi, daha özelde beyinde gerçekleşen bir takım fonksiyonlarla da açıklanmayı gerektirir. İşin ilginç yanı okuma eylemi sadece beyinde değil ayrıca insan vücudunda gerçekleşen başka işlevlere benzetilerek de açıklanmaya çalışılmıştır. Özellikle okumanın yeme eylemine sıklıkla benzetilmesi altı çizilmesi gereken bir durumdur. Bununla birlikte bizler anlıyoruz ki vücudumuzun gıdası yemek iken zihnimizin gıdası da fikirlerdir. Bu beslenmeyi en uygun sağlayan eylem ise okumadır. Bazı konular "ham bulunur, sulandırılır; tartışmaya tuz biber ekilir; yazıdan lezzet alınır veya kitap sindirilir" (Manguel, 2013, s. 205).

Neil Postman önemli kitabı Televizyon: Öldüren Eğlence'de (2012) matbaanın baskın olduğu dönemi "Yorum Çağı" olarak isimlendirmiştir. Yorum, örüntü tanıma ya da okuma kelimeleri farklı zamanlarda ve konuya eğilen kimselere tarafından aynı anlamda kullanılmıştır. Yorumlama düşüncenin güçlendiği bir seviyedir ve bu seviyeye çıkmak için yazının söylemi olgunlaştırmış olması gerekmektedir. Fonetik alfabe tam olarak bu işlevi yerine getirmektedir. "Buna, gelişmiş bir kavramsal, tümdengelimci ve ardışık düşünme yeteneği, akla ve düzene büyük değer verme eğilimi, çelişkiden nefret etme, mesafeli ve nesnel yaklaşma becerisiyle gecikmiş tepkiye hoşgörü ile bakma tavrı da dahildir" (Postman, 2012, s. 76). Goody'nin deyimiyle yazılı metnin sağladı̆̆ı sondan başa doğru tarama imkanı yazılanı tutarsızlıklardan arındırmayı (Goody, 2013, s. 83), düşünce ve söze yeni ayrımcı güç yükleyerek kelimelerin eleştirel ve titiz seçimini mümkün kılar (Ong, 2007, s. 126).

\section{2. İçeriğe Yön Veren Unsurlar Olarak Basılı ve Dijital Ortamların Özellikleri}

Ortam ve içerik ilişkisine şimdiye kadar pek çok araştırmacı dikkat çekmiştir. Ancak en büyük etkiyi "mesaj aracın kendisidir" sözü ile Marshall McLuhan (1994) yapmıştır. McLuhan'a göre iletişim aracının yapısı iletişimin biçimini ve yoğunluğunu belirler. Ortaya çıkan iletişim biçimi ise insan duyularının bazılarını daha fazla çalıştırır ve farkettirmeksizin insanın duyusal evrenini biçimlendirir. Çünkü her bir teknoloji insan organlarının bir uzantısıdır ve son aşamada onları pekiştirirler. Tekerlek insan ayağının, mikrofon dilin, yazı gözün, söz kulağın uzantısıdır. "Teknoloji düşünceler ve kavramlar düzeyinde etki etmez; ancak anlam ilişkilerini ve algılama modellerini yavaş yavaş ve en küçük bir direnişle karşılaşmadan değiştirir" (McLuhan, 1994). Bu bağlamda basılı kitap içeriğiyle değil biçimiyle bilgiyi kişiselleştirir ve cemaate ait olanın çerçevesini bireysele doğru çevirerek modern toplumun zeminini oluşturur (Maigret, 2016, s. 130).

Bilinen ilkyazı örnekleri Sümer tabletleridir ve belleğe yardımcı olmak amacıyla ortaya çıkmışlardır (Jean, 2015, s. 13). Bulunan ilk şekiller birinci dereceden ifade edilmek istenene gönderme yapmakta, örneğin bir üçgen dağ anlamına gelirken ters A harfi boynuzu andırdığından öküz anlamına gelmektedir (Sanders, s. 2012). Şekilleri kullanan topluluklar zamanla artmış ve şekil kullanımının farklı türleri ortaya çıkmıştır. Sonrasında sesleri karşılamaya başlayan kullanımlar üretildi ve fonetik alfabe doğdu. Fonetik alfabe ise edebiyatın, hukukun ortaya çıkmasını ve dolayısıyla daha sofistike toplumların, yönetimlerin ortaya çıkmasını beraberinde getirdi. Bu süreçte yazı kil tabletler, taşlar, papirüs ve parşömen üzerine kaydedilmiştir. Yazının kaydedildiği yüzey basitleştikçe, ucuzlaştıkça ve kullanışlı hale geldikçe içerik yavaş yavaş dini konulardan, yönetsel prensiplerden uzaklașarak kișisel alanlara, edebiyata ve felsefeye doğru kaymıştır. Görsel forma taşınan ve yaygınlaşan söz, ifade veya anlam yazı ya da çizi gibi bir görsel unsurla birleşmeye başladıktan sonra birden fazla duyuyu anlamı oluşturmaya çağırmaktadır. Anlam zaman içerisinden genişler ve derinleşir. Zihinde kalıcılığı artar 
ve kolay hatırlanır. Alberto Manguel'in de söylediği gibi "okuyabilmek tamamen yeni bir duyu edinmek gibiydi. Artık kimi şeyler yalnızca gözlerimin görebildiği, dilimin tadabildiğiyle sınırlı değildi. Bedenimin, anlamını çözebildiği, seslendirebildiği şeylerdi" (Manguel, 2013, s. 19).

Okuma eyleminin bilinci şekillendirmesine etki eden unsurlardan birisi de kitabın yazılı olduğu yüzeydir. Yüzeyin yapısı, taşınabilirliği, not almaya uygun oluşu, sayfalar arasında geçiş yapabilme olanağı okumayı kolaylaştırabilir ya da zorlaştırabilir; yüzeyin metni yansıtma kapasitesi, genişliği ve kullanışlılığı da metnin insan zihinde bütünsel olarak kavranmasında etkilidir. Basılı bir kitabın okunması eșsiz bir deneyimdir. Kitabın kokusu, kıvrımları, üzerindeki izler anlama eşlik ederek, oluşturduğu duygu ve düşüncelerle birlikte insan zihnine kazınır ve bu sayede deneyimin biricikliğini pekiştirmiş olur. Dijital cihazlardaki kaydırmalı ve ekrandan okuma, basılı okumanın eşsizliğini ve biricikliğini azaltmaktadır. Okunan sözcüklerin zihinde canlandırılmasıyla oluşan duyumsamaya eşlik eden dokunma duyusu, belki kitabın sayfalarına, mürekkebine, yaşına bağlı olarak oluşan kokusuyla gelen koku alma duyusu artık metalik ya da plastik bir nesne üzerinde erimektedir. Kitapları ve hatta bazı sayfaları üzerlerinde oluşan kırıșıkla, kırılmayla, üzerlerinde bir lekeyle birlikte bize anlatmak istediklerini iç içe geçmiş olarak hatırlarız.

Zemin, duyumsal uzamın sunduğudur. Sözün ve kulağın egemenliğindeki uzam bir zemindir. Bu zeminin üzerinde sözcükler var olurlar. Yazının egemenliğinde, matbaa ve tipografinin bir uzamı vardır ve yazı bu zeminin üzerindeki figürdür. Zemin bir duyu üzerine oturmaktadır ve zemin elektriğin icadına dek kulak veya göz idi. Ancak elektrik ile iletişim araçlarının ortaya çıkmasıyla zemin parçalanmıştır. Birden fazla duyudan beslenen zemin söz konusudur. Tek bir duyumdan oluşmayan modern elektrik çağında figür zeminden kopmaktadır. Çünkü modern öncesi iletişim zeminin önce gelip kurulduğu ve figürün bu zemine inşa edildiği bir ardışıklıkla oluşmaktadır. Elektrik sonrası iletişim araçları çok parçalı bir duyumsal evren talep ederler.

McLuhan elektriğin iletişimi hızlandırması ve anlık hale getirmesi ile insanın sol beyninin ağırlıklı olarak kullanıldığı yazılı kültürün dayandığı bilişsel yapının yıkıldığını ve yerine "hepsi ve bir andalık" mantığı ile çalışan "sağ beyin" modelinin kurulması gerektiğini söylemektedir. Ses, yazı, imajlar, video, grafikler ve diğer dijital iletişim unsurları dijital ortamda bir anda sunulmaktadır (2001, s. 25). "Elektriksel olarak konfigüre edilmiş bir toplumda, otomobillerden bilgisayarlara kadar üretim ve dağıtım için gerekli bütün kritik enformasyon, herkes için aynı anda ulaşılabilirdir. Kültür, tıpkı bir elektrik devresi gibi organize olur; ağdaki her nokta, diğer bir nokta kadar merkezseldir" (McLuhan, s. 153).

Dijital ortamlar da tıpkı gerçek ortamlar gibi insanı yönlendiren bir yapıdadır; bir mimariye sahiptir. Mimari bazı tercihleri sunarken bazılarını da ortadan kaldırır. Mekanda var olanın dışında tercih edilebilir olan yoktur. Bir başka deyişle seçme özgürlüğü var olan ile sınırlıdır. Bu durumda iletişim ortamında etkileşimin kaçınılmaz bir yönü, hızı söz konusudur; ortamlar belli biçimlerde iletişim kurmaya yönlendirmektedir. (Çomu ve Halaiqa, 2014, s. 31).

Ortamların içerik üzerinde etkisini tartışanlar sadece eleştirmenler, araştırmacılar veya sosyal bilimciler değildir. Sosyal ağların profesyonelleri de kullanıcılara ortamın sunduğu imkanları kullanarak etki etmenin yolarını öğrenmişlerdir. Bu bağlamda sosyal ağların arayüzlerinin mimarisi ön plana çıkmaktadır. Eski bir Facebook data analisti olan Andrew Ledvina önemli itiraflarda bulunmuştur. Ledvina Facebook'un kumarhaneden farklı olmadığını ifade etmekte ve iddiasını da Facebook'un kullanıcılarına zamanın 
nasıl geçtiğini hissettirmemeye çalışmasına dayandırmaktadır (Hill, 2014). Gerçekten de Facebook veya diğer sosyal ağlar kullanıcılarına ilgilenebilecekleri o kadar çok alternatif sunar ki insanlar karşılaştıklarının gerçekten bakılması, görülmesi gereken şeyler olduklarını düşünürüler. Zaman kavramı unutturulmaya çalışılır. Kullanıcılar olarak bizler yoğun bir haber akışına maruz kaldığımız için algımız karmaşıklaşır ve bu akışa kendimizi kaptırırız. Alışık olmadığımız akış bizi bağımlı ve takıntılı yapar, bilincimiz yoğun akışı işleyemez ve yorulur. Bu durum aslında bildiğimiz bir şeydir. Televizyon da benzer bir mantıkla çalışır. Hızla değişen ekran görüntüsü ve temposu ile bizleri bir sonraki reklam kuşağına kadar bağlamayı umar.

Dijital kültürde iletişim olanaklarının açtığı bir başka pencere ise iletişim unsurlarıyla bir oyun hamuru gibi oynanmasına müsaade etmesidir. İletişim unsurları birbirinden ayrılır, parçalanır, koparılır ve yeniden birleştirilir. Her birleştirme yeni anlamlar ifade etme yetisindedir. Tüm medya nesnelerinin sayısal ikili kodlardan oluştuğu ortamlarda 'rakamsal gösterim'; resim, ses, biçim veya davranış gibi yeni iletişim ortamları unsurlarının ayrı örnek koleksiyonları olarak temsil edildiği durumlarda 'modülerlik'; resim işleme yazılımlarında resimlere filtre uygulamak gibi yeni iletişim ortamları unsurlarını önceden programlanan şablonlar veya algoritmalarla üretme veya değiştirme olasılığında 'otomasyon'; yeni iletişim ortamları nesnelerinin sabit veya değişmez olmadığı düşünüldüğünde, yani daha eski medyaya benzemeyen yeni iletişim ortamları nesneleri bir şeyin farklı sürümleri olarak var olabileceğinden 'değişkenlik'; bir resmin renklerinin sese dönüştürülmesindeki gibi bir şeyin diğer bir şeyin biçimine tercümesinde 'kod çevrimi', dijital kültürde iletişimin yeni unsurlarıdır (Köroğlu, 2012. S, 13- 14).

\section{Yazııı İçeriğin Basılı ya da Dijital Ortamlarda Bulunmalarına Göre Değiş̧en Özellikleri}

Bir mesajın, yazılı veya işitsel iletişim unsurunun anlamı içinde bulunduğu ortama göre farklılık gösterir. Bu farklılığı Neil Postman "Bence her iletişim aracının (medium) bir rezonansı vardır, zira rezonans apaçık bir metafordur. Kullanımının asıl ve sınırlı bağlamı ne olursa olsun, bir aracın (medium) bu bağlamı yeni ve beklenmedik bağlamlara taşıma gücü vardır" (2012, s. 27) biçiminde açıklamaktadır. Her aracın kendisine has bağlamı vardır. Bağlam iletişim unsuru sunulmakta iken kendisini gösteren bir düzlemdir. Örneğin bir kelime söz ile ifade edilmeden, bir yere yazılmadan var olamaz; sözü ya da yazıyı sunacak olan ortamın da iletişim sürecine etkisi bağlamında değerlendirilmesi iletişim sürecinin gerçekleşmesi ile mümkündür. Ortam ve içeriğin birleştiği anda ortaya çıkan anlam aynı zamanda rezonansın da oluştuğu anlamdır. Rezonans söz konusu anlama içkindir ve orada saklıdır. Farkında olmak için iletişim sürecine yakından bakmak şarttır. "Araç (medium), biz zihinlerimizi düzenleyip dünyaya ilişkin deneyimlerimizi bütünleștirmeye yönelttiğinden kendini bilincimize ve toplumsal kurumlarımıza melez biçimlerle kabul ettirmeye çalışır" (2012, s. 27).

Yazılı içerik rasyonelliğine vurgu yapan niteliktedir ve yazılı sözün ardışık, önermeci karakteri bilginin analitik biçimde işlenmesi olgusunu güçlendirmektedir (Ong, 2007). Yazı sayesinde sınıflandırma, sonuç çıkarma ve akıl yürütme becerileri artmaktadır. Yazılı sözü benimsemek, yalanları, kafa karıştırıcı sözleri ve aşırı genellemeleri açığa çıkarmak, mantık ve sağduyu istismarlarını saptamak, ayrıca fikirlerine ağırlık vermek, savları birbirine karşılaştırmak, bir genellemeyi diğerleriyle ilişkilendirmek demektir" (Postman, 2012, s. 63-64).

Basılı içeriğin oluşturduğu bütünlüklü yapı, düşünme ve akıl etme biçimi ilk olarak telgraf tarafından sarsılmıştır. İlgisizliği, etkisizliği ve tutarsızlığı hızlı biçimde üretip 
yaymaya başlamıştır. Sindirilmesi mümkün olmayacak büyüklükte verinin toplanarak insanların önüne gelmeye başlaması "bilgi" kavramının da niteliğinde değişiklikler meydana getirmiştir. Bağlam yitmeye başlamış, bilginin değeri günlük ve hatta anlık faydalara indirgenmeye başlanmıştır. Telgraf sayesinde daralan mekan zaman algısında da sıkışmalar oluşturmuştur. Bilginin efektif ve ticari yönü önem kazanmıştır. Avantaj yaratan, yenilik sağlayan, ilginç olan değerli konumuna yükselmiş, kadim olan geri plana itilmiştir. Satılmak zorunluluğu olan gazeteler için toplanan haberlerin başlıkları aklı değil duyguları önemseyen bir tarzı yansıtmaktadır. Bir haber aynı sayfada başka bir haberle yan yana verilirken içeriğin tutarlılığı kaybolmuştur. Farklı olaylar, içerikler peş peşe gelmektedir. Okuyucular aynı anda birden fazla bilişsel tutumu geliştirmeye ve duygusal tepki vermeye zorlanmaktadır. Ayrıca yaşadıkları hayatta kendileri için gerekli olmayacak, ilgisiz içeriği bir şekilde konumlandırmak zorunda kalmışlardır. "İnsanlar bir zamanlar enformasyona gerçek hayat ortamlarını kendileri yönlendirebilmek amacıyla ihtiyaç duyarlarken, şimdilerde aslında hiçbir işe yaramayan enformasyonların görünüşte yararlı olabilecekleri bağlamları yaratmak zorunda kalmaktadırlar" (Postman, 2012, s. 89). Bu konumlandırma çabası gerçek bir çaba olmadığından, zorlama olduğundan enformasyonun okur tarafından oturtulacağı bağlam Neil Postman'ın da söylediği gibi sahtedir. "Sahte bağlam, parçalı ve havada kalmış enformasyonlara görünüște ișe yaramalarını sağlamak amacıyla tasarlanmış bir yapıdır. Ancak sahte bağlamın sağladığı yarar ne eylem ne bir problemin çözümlemesi ne de değişimdir" (s. 90). Bağlamın kopan bilginin kalitesi sönümlenmekte ve amacı yitmektedir. Bu durumda var olan içeriği seyrelmiş, vülgarize edilmiş bir içerik elde kalmaktadır.

Kitaplar ya da basılı materyaller uzun bir hazırlanma sürecine tabidirler. Buradaki birikim zamanın imbiğinden geçerek demlenir. İçeriğin taşınacağı ortamın kıymetli olması hata riskinin en aza indirilmesi için önemli bir etkendir. Hata demek maddi zarar demektir. Dikkatli biçimde yazılmış bir kitabın, düzenlemiş bilginin okunması da uzun ve emek isteyen bir süreçtir. Bu uzun süreçte insan beyni, bilinci konuya konsantre olmadan bilgiye arzulanan düzeyde erişemez. Birbirini tamamlayan bölümler, referanslar, metinlerarası göndermeler okuyucu için aşılması gereken zorluklar, çözülmesi gereken düğümlerdir. Bazen yazarın bilinçli bir tasarımı bazen de konunun gereği olarak anlam, püf noktalar satır aralarına gömülür. Bütün bu süreç boyunca genel ve tam bir amaç kitap boyunca çizgisel olarak izlenebilir konumdadır. Analitik düşünme, bütünlükçü bakış açısı olmaksızın metin kuru bir fonetik kalabalıktan ibarettir. Bu yoğun çözümleme ve düşünme süreci insan beyninde sinapslar ve eksonlar olarak belirmektedir (Eagleman, 2016). Bir saat veya gün boyunca zihnin meşgul olduğu fiziksel ve görsel vücuda sahip metinsel yapı yoğun bir duyusal süreci geride bırakırken metinde olan içeriğin bir kopyasını insan beynine işler. $\mathrm{Bu}$ içerik insan beyninde sahip olduğu büyüklük, anlamlılık ve tutarlılıkla orantılı olarak kolayca hatırlanabilir, kullanılabilir durumda olacaktır.

Dijital ortamda yazının miktarı artmış ancak içerik kalitesi düşmüştür. Bununla birlikte, yazı, dijitalleşme ile birlikte görsellerle daha fazla yan yana gelmiş, birlikte sunulmaya başlanmıştır. Ses kayıtları, videolar, grafikler, animasyonlar yazıdan rol çalmıştır. Her yeniliğin iki ucu olduğunu, olumlu ve olumsuz etkilerinin bulunduğunu unutmamak gerekmektedir. İçerik çeşitlenirken duyusal evren giderek parçalanmaktadır. İçerik rezonanslar yaparak yeni anlamlara kavuşmaktadır. Yazının aldığı yeni biçimlerden birisi de hipermetin özelliğidir. Hipermetinler birden fazla metnin iç içe geçerek aralarında linkler vasıtasıyla hızlıca geçişlerin yapılabildiği, metin içinde metnin açıldığı yazım türleridir (Dijk, 2018, s. 24). 
Hipermetinlerde okuma șekli doğrusal değildir. Bir sayfadaki yazıyı tam olarak bitirmeden başka bir yazıya, oradan bir görüntüye geçilir. Klasik anlatının şekli olan, giriş gelişme sonuç, dijital kültürün dönüştürdügü metin anlayışında silikleşmektedir. Dijital medyanın yazıya getirdiği bu yenilikle insan zihnini şimdikinden daha parçalı bir yapıya dönüştüreceğini, bütünlügü̈n azalırken kopuklukların arttığı bilinç yapısının ortaya çıkaracağı öngörülmektedir. Söz konusu bilinç aynı zamanda çoktan seçmeli bir medya ortamında tercihlerini yaparak ilerlemek durumundadır. Aşağıya doğru akan ve size devam etmeniz için farklı yollar da sunan ekranda yazı, görüntü, fotoğraf veya grafiklerin hepsi aynı anda, aynı sayfada sunulmaktadır. Linkler aracılığıyla size isterseniz geçiş yapabileceğiniz tercih alanları verilmektedir. Bu anlamda okuyucudan kullanıcıya evrilen dijital kültür insanı tercihler yaparak ilerlemektedir (Asutay, 2009, s. 71).

Basılı ortamlarda yazı mekana sabitlenmiștir ancak dijital ortamlar yazının tekrar ve tekrar hem değiştirilebileceği ve sonsuza kadar çoğaltılabileceği ortamlardır. Basılı ortamlarda yazar ve okurun konumları son derece belirgin iken dijital ortamlarda yazar ve okur arasındaki sınır ortadan kalkmıştır, ilişki giriftleşmiştir. Dijital kültürde okur sadece okur değil aynı zamanda yazar ve kullanıcıdır; metni alıp tekrar değerlendirmektedir. Okur metni parçalara bölebilmekte, çoğaltabilmekte, eksik gördüğü yerleri tamamlayabilmektedir. Okurlar internet ortamında bir araya gelerek müşterek metinler olușturabilmektedirler (Chartier, 1997, s. 215).

Dijital kültürün yazıya kattığı en yeni boyutlardan birisi şüphesiz "ağ yazını"dır. İnternet üzerinden herkesin katkı yapmasını mümkün kılan etkileşimli, interaktif yapı sayesinde insanlar aynı metne katkı koyabilmekte, onu oluşturabilmektedir. İnternette bu şekilde oluşturulan öykü ve romanlar bulunmaktadır. Birden fazla yazar tarafından oluşturulan bu metinler bildiğimiz anlamdaki, geleneksel metin anlayışını altüst eder. Sürekli yenilenir, eklemelere açıtır. Sonsuza kadar uzanan bir serüvene sahip olma potansiyelleri vardır. Geleneksel yazınla karşılaştırdığımızda karşımıza tamamıyla yeni bir "durum" olarak çıktığını söyleyebiliriz. Bu yeni durumun en iyi örneklerinden birisi kuşkusuz Wikipedia'dır. Birden fazla yazar ile her an büyüyen, gelişen, değişen, son derece dinamik bir yapıdadır ve aynı zamanda doğrusal değildir. Linklerle, fotoğraflarla içerik desteklenmekte, okuyucuyu bir kullanıcı konumuna getirmekte, tercihlere sürüklemekte, sayısız farklı okuma alternatifi barındırmaktadır.

Dijital kültürde görme duyusunun ve görselliğin ağırlığı giderek artmaktadır. Bilgisayar ilk ortaya çıktığında mevcut teknik imkanların sonucu olarak dijital ortam yazı ağırlıklıydı. Bilgisayar ve optik teknolojisinin gelişmesi çoklu medya ortamının dijital ortamda sağlanmasını beraberinde getirmiștir. 1990'lı yıllarla birlikte webin yaşadığı ticarileşme süreciyle birlikte dijital ortam içerik olarak hızla zenginleşmeye ve çeşitlenmeye başlamıştır. Grafiklerle zenginleştirilmiş hipermedya arayüzleri ses, görüntü, metin, grafikler gibi unsurları içeren dosyalar kullanılmaya başlanmıştır. Bilgisayarlar grafikleri, görüntüleri, sesleri işlemeyi ve aktarmayı geliştirdikçe bilgisayarın kullanımı yaygınlaşmıştır. Ağlar dosyaların daha hızlı aktarılmasını mümkün kılacak biçimde teknolojik alt yapı yenilenmiş, güçlendirilmiştir. Resimleri, metni, işitsel olanı ve diğer verileri çoğunlukla merkezsizleştirilmiş bir yapıda birbirine bağlayan bir sistem olarak hipermetinsellik, internette yaygınlaştı ve gelişti (Dursun, 2013, s. 171).

Dijitalleşme ile birlikte geleneksel olarak nitelenen iletişim araçlarının özellikleri bir yanıt üzerinde toplanmakta, yakınsanmaktadır. Yakınsamanın gerçekleştiği dijital iletişim aracı mobildir ve her an her yerde kullanıma hazırdır. Birden fazla katılımcının, 
aynı anda, görüntü, ses, yazı, grafik gibi iletişim unsurlarıyla katılabileceği çoklu ortamlar sunmaktadır. Dijital ortam sunan aygıtlarda fotoğraf, görüntü, ses gibi iletişim unsurlarını kendiniz kaydedip şekillendirip paylaşabilmek, başkalarından alınan içeriğin de yeniden şekillendirmesi mümkündür. Bu doğrultuda, günümüzde elektronik kitaplar basılı kitapların tüm özelliklerini taşımasının yanı sıra kendine özgü yeni özelliklere de sahiptir. Yeni özellikler metni zenginleştirmenin dişında okura da metni kendi istediği formda okuma imkanını verir. Okur basılı bir kitapta herhangi bir değişikliğe gidemezken elektronik kitaplar kendilerini kişiye özel biçim yaratmalarını sağlayarak okumayı da bir oyun havasına sokar. Sayısal kitabın bu konudaki avantajı tasarımın teknolojik açıdan değiştirilebilir olmasıdır. E-kitaplarda yazı fontu, boyutu ve satır aralığı, sayfanın arka plan rengi ve parlaklığı okurun isteğine göre istediği kadar düzenlenebilirdir. Basılı kitaptaki gibi metin içi işaretleme, not alma yapılabilir ama basılının tersine işaretleri ve notları geri alma seçeneği de vardır. Metin içinde basit arama seçenekleri ile istenilen bölüme rahatlıkla gidilebilmektedir. Basımevine bağlı kalmadan istenildiği gibi bir biçime çevrilen metnin çıktısı alınarak basılı da kullanılabilir. Ayrıca e-kitaplar hiperlinklerle destelenmektedir. Dolayısıyla okur bir kaynaktan diğerine rahatlıkla geçiş olanağı elde etmektedir. Ayrıca e-kitaplar raf ömrü veya fiziki yapısına göre depolama sıkıntısı yaşatmamaktadır. Okur kendi dijital kütüphanesini e-kitap okuyucusu ile istediği her yere götürebilmektedir.

\section{Ortamların Şekillendirdiği Bilinçıerin Özellikleri}

Bir kültürün içinden veya dışından bir teknoloji başlatılır ve bu teknoloji duyumlarımızdan birine ya da diğerine yeni bir vurgu ya da üstünlük verirse, bütün duyularımız arasındaki oran değişir. Artık ne eskiden hissettiğimizin aynısını hissederiz, ne de görme ve duyma duyularımız olmak üzere diğer duyularımız aynı kalır. Anestezi koşulları dışında, duyularımız arasında sürekli bir etkileşim vardır. Ama herhangi bir duyu, yüksek bir yoğunluk düzeyine çıkarıldığında, öteki duygular üzerinde anestetik bir etki yapabilir.

Pek çok yazı türü birer medya olarak kullanılmıştır. Mısırlıların kullandı̆̆ı hiyeroglifler ya da ideografik Çin yazısı kullanılan başlıca alfabelerdir ancak hiçbirisi fonetik alfabenin yarattığı bilişsel etkiyi yaratamamış, o denli devrimci olamamışlardır. McLuhan'ın (2001) dediği gibi yazı ile ifade ettiği anlam arasında kesin bir kopuş söz konusu bilișsel kırılmanın nedenidir. Bütün alfabeler arasında sadece fonetik alfabe, göz ile kulak arasında, semantik anlam ile görsel kod arasında bir kopukluk yaratır; dolaysıyla, insana bir kulağa karşılık bir göz verme ve onu kabile ortamından uygar ortama nakletme gücüne sahip olan da, tek başına fonetik yazıdır. Çin kültürü, Batı dünyasından her zaman hatırı sayılır ölçüde daha rafine ve kavrayıcı olmuştur. Oysa Çinliler kabilseldir, kulak insanıdır. "Uygarlık” artık teknik olarak, kabile bağlarından kopmuş, görsel değerlerin düşünce ve anlam örgütlenmesinde birincil önem kazandığı insanı tanımlamak için kullanılmak zorundadır. Bu, "uygarlığa" yeni bir anlam ya da değer vermek değil onun karakterini saptamaktır (McLuhan, 2001, s. 41-42).

\footnotetext{
"Duyulardan birinin ya da ötekinin fonetik yazı gibi mekanik araçlarla genişletilmesi, bütün meydana getirdiği kaleydoskop açısından bir çeşit burkulma gibi görünebilir. $\mathrm{Bu}$ durumda mevcut unsurların yeni bir kombinasyonu veya oranı ortaya çıkar. Ve muhtemel biçimlerin yeni bir mozaiği kendisini gösterir. Dişsal teknolojinin her örneğiyle birlikte duyu oranlarındaki böyle bir burkulmanın kendini gösterdiği farketmek, bugün artık kolaydır. Daha önce neden farkına varılmamıştı? Bunun nedeni belkide geçmişteki değişikliklerin biraz daha yavaş meydana gelmesiydi. Bugün kendi dünyamızda bile bu türden yeni teknolojiyi yaşıyor olmamızın yanı sıra, duyularımızın duruşunu ve ilişkilerini değiştirmek konusunda yeni
} 
enformasyon teknolojilerinin rolünü ancak çok büyük bir ilgisizliğin gizleyebileceği pek çok başka kültürü de gözlemleme olanağına da sahibiz" (McLuhan, 2001 s. 80-81).

Eski, çok katmanlı, üst düzeyde işlevselleşmiş örgütlenmeler, "düşünmenin" "yapmadan" ayrılmasıyla nitelendirildi; düşünme, genel olarak, piramidin altından çok tepesine yerleștirilir ve "cephe" unsuru olarak değil "kurmay" unsuru olarak görülürdü. (McLuhan, 2001, s. 198-199)

Gutenberg'in matbaayı icat etmesiyle dönüşüme uğrayan düşünme ve akletme biçimimiz doğrusal bir niteliğe bürünerek bilimin, sanatın ve kültür hayatının merkezine kurulmuştur. Doğrusal akıl Rönesans'ın hayalci aklı, Aydınlanma'nın rasyonel aklı, Sanayi Devrimi'nin icatçı aklı ve hatta modernizmin yıkıcı aklı şekline girebilmişti. Çünkü doğrusal akıl söz konusu biçimleri içerisinde barındırabilecek kadar geniş, çok yönlü ve esnektir. Bununla birlikte insanlık, McLuhan'ın radyo ile başlayan ve televizyonla devam eden elektronik merkezli bir iletişim modelinin alışkanlıkları ve düşünme biçimini değiștireceğini söylediği zamanda yeterince yol almıștır. Bir düşünme biçiminden diğerine geçilmektedir. Matbaa ve kitap temelli doğrusal akıl dijital kültürün getirdiği dijital akılla değiştirilmektedir. Sakin, odaklanmış, dikkati dağılmayan, doğrusal akıl; kısa, kesintili, çoğu zaman kesişen patlamalarla parça parça bilgi almak isteyen ve sanki buna ihtiyacı olan yeni bir tür akıl tarafından kenara itilmiștir (Carr, 2012, s. 23). Dijital kültürde "daha iyi" artık "daha hızlı" anlamına gelmektedir. İnternette dolaşırken topladığı bilgi parçaları tarafından sarhoș olan insanlar "olduğu" şeyden "dönüștüğü șeye" doğru bir bakıș, bir iç görü gerçekleştirememektedir.

İnsanlar deneyimlerini, becerilerini, anılarını kısacası zihinsel her şeylerini beyinlerinde gerçekleștirirler. Deneyimin yoğunluğuna paralel olarak beyinde sinirsel bir yapı oluşur. Kitap okurken oluşan sinirsel yapı ile dijital aygıtları kullanırken oluşan sinirsel yapı ve bunların beyinde yapılandıkları bölgeler farklılık gösterir. İnsan beynindeki sinir hücreleri olan nöronlar aksonlar ve dendritler denilen bağlar üzerinden birbirlerine elektriksel uyarı alırlar veya gönderirler. Bir nöron aktifleșerek bașka bir nöronla bağ kurmak istediğinde merkezinden gelen elektriksel enerji hücrenin aksonunun ucuna akar ve burada nörotaşıyıcı adı verilen kimyasal salgılamasını sağlar. Nörotaşıyıcılar, bir nöronu başka bir nörona bağlayan köprü vazifesi gören sinapslar üzerinden taşınır ve elektriksel akım diğer nöronun dendritine ulaştırılarak bağ kurulmuş olur (Eagleman, 2015). Nöronlar sinapslar üzerinden birbirleriyle bağ kurarak karmaşık bir beyin yapısını oluştururlar. Düşüncelerimiz, anılarımız ve duygularımız nöronların sinapslar üzerinden kurduğu elektrokimyasal iletişim neticesinde oluşur (Carr, 2012, s. 34). Kafatasımızda yaklaşık 100 milyar nöron bulunmaktadır ve her bir nöron ortalama bin sinaptik bağlantı kurarken bu sayı bazı nöronlarda 100 bin bağlantıya kadar çıkmaktadır. Bununla birlikte insanlar uzunca zaman insan beyninin değișmeyen bir yapıya sahip olduğu inancına sahipti. Çocukluk ve ergenlik sürecinde beyinde çalışma mekanizması oluşmakta ve bir daha değişmemekte, zamanla yaşlanarak erozyona uğradığına bunun da beynin yaşadığı yegâne değişim olduğunu düşünülmekteydi. Ancak daha sonra yapılan araștırmalarda insan beyninin sürekli bir yenilenme ve uyum sağlama sürecinde olduğunu ortaya koymuştur. Nöronların kullanımla gelişebileceği, büyüyebileceği ve kullanılmaması durumunda yok olabileceğine dair bulgular ortaya konulmuștur (Carr, 2012: s. 35; Eagleman, s. 2015; Ramashandran s. 2012).

İnsan deneyimi gerçekleştikçe, kendisine sinir siteminde yer etmektedir. Her bir deneyim, davranış, eylem insan beyninde yeni bir bağ demektir. Aynı eylem sıklaştıkça 
insan beyninde bağlar da sıklaşır ve müstakil bir deneyim olmaktan çıkarak alışkanlığa dönüşmektedir. Bağlar ne kadar kuvvetlenirse alışkanlık da o kadar güçlü olmaktadır. İnsan beyni güçlü olan alışkanlık üzerinden hareket etmeye yatkındır çünkü güçlü olan ezbere dönüşmektedir ve ezberlenen davranış bilişsel olarak yük oluşturmamaktadır.

\begin{abstract}
"Akan su kendisine bir kanal oluşturur. Su kanaldan aktıkça kanal derinleşir ve genişler. Daha sonra tekrar aktığında önceden açılan yolu takip eder. Aynı şekilde dişsal nesnelerin iz düşümleri sinir sistemi içinde kendileri için gittikçe daha uygun yollar oluştururlar ve bu hayati yollar belirli bir süreliğine kesintiye uğramış olsa bile benzer dıșsal uyarılar altında tekrar ortaya çlkar (Carr, 2012, s. 36)."
\end{abstract}

İnternet yaygınlaşana kadar kullandığımız bütün teknolojiler ya kulağa, ya göze ya da televizyonla birlikte kulağa ve göze aynı anda hitap etmiştir ve sınırlı bir duyumsal etkileşimlilik söz konusudur. İlk medya olarak kelimeleri ve hatta bugün kelime olarak bir anlam ifade etmeyen bazı sesleri bile temel alacak olursak, en başından itibaren medya tarihi duyu organlarımıza yönelim bağlamında bölünmeler, parçalanmalar tarihidir. Basılı medyalarda ses ve görüntü olmazken, radyoda sadece ses vardır. Televizyon ise doğası gereği akan görüntü üzerinden içerik oluşturmuştur. Kitaplar güvenilir ve kapsamlı kaynakladır. Bugünse internetin sağladığı imkanlar sayesinde artık bütün medyalar tek bir yerde toplanmaktadır.

Dijitalleşme ile birlikte artık tek bir aygıtla farklı türde içeriklere erişilebilmektedir. Yaşanan bu yakınsamanın bir diğer boyutu ise hızdır. Hız ise zihnin aynı konu üzerinde gerektiği kadar uzun süre kalmasını engellemektedir. Sırada bekleyen onlarca erişilecek ve göz atılacak malumatın olmasının bir sonucu olarak yüzeysellik yeni vasat haline gelmiştir. Sweller'a (1999) göre kısa süreli hafızanın üzerindeki aşırı yük önemli bilgiyle önemsiz olanın ayırt edilmesini zorlaştırmaktadır. $\mathrm{Bu}$ aşırı yükün kaynağı gereksiz problem çözme ve dikkat dağıtan etmenlerin çokluğudur. Dijital iletişim araçlarını kullanan insanlar bu iki unsura fazlaca maruz kalmaktadır. Bilgi parçalı, kesik ve eksik, uyaranlar ise devamlı ve farklı duyumsallıktadır. İnsan beyni yeni duruma sahip olduğu esneklik sayesinde uyum gösterdiğinde ise derinlemesine düşünme yeteneğini tamamen kaybedecektir (Sweller, 1999, s. 22). Bir şeyi kavramak için okuma yapmak, çıkarımlar yapmayı, daha önceki öğrendiklerimizle o anda karşılaştığımız bilgilerin uyumluluğunu gözetmeyi, kavramlar arasında ilişki kurmayı, fikirleri sentezlemeyi ve özümsemeyi gerektirmektedir. Dijital medya aşırı bilgi yüküyle basılı kültürün zihinsel süreçlerini erozyona uğratarak kendi sinaptik yapısını ve bilişsel süreçlerini inşa etmektedir.

İnternette gezinmek, zihnin yoğun ve çoklu görev yapmasını gerekli kılar ya da bizi buna yapmaya zorlar. Kısa süreli belleğimizi yorar ve beynimizi bir şeyden başka bir şeye geçişe, sürekli kararlar vermeye, dikkati kesik biçimde kullanmaya alıştırır. Dikkat bir defa odaklanıp devam ettiğimizde değil, kesilip tekrar odaklandığımızda daha fazla bilişsel bir yük yüklenmiş oluruz. Beyin hedeflerini değiştirmek, yeni görev için gerekli kuralları anımsamak ve önceki, hala canlı aktiviteden arta kalan kognitif müdahaleleri önlemek için zamana ihtiyaç duyar. İnternet ortamında bir görevden diğerine geçiş yapan beynimiz şimdiye kadar sahip olduğu özelliklerden daha başkalarına ihtiyaç duymaktadır. Yeni durum insanın bilişsel gücünü zorlamaktadır.

Ne kadar çoklu görev yaparsak hedef odaklı çalışmalarımız o kadar azalacaktır. Sorunun kaynağına inmek çoğu zaman çaba ve zaman ister ve bu şekilde yaratıcı düşünceyi üretebilir, sorun çözebiliriz. Dijital iletişim araçlarıyla gelen zihinsel çalışma yöntemleri neticesinde gelecekte yenilikçi fikirlerin çok az ortaya çlkacağl, insanların geleneksel 
olanı taklitle yetineceklerini öngörülmektedir. Zamanla çoklu görev yapma konusunda insan beyni giderek ustalaşacak ve bir takım olumsuzlukları giderecektir ancak dikkati bir noktadan diğerine odaklama alışkanlığının beynimizi ele geçirmesi neticesinde ustalıklarımız yüzeyselleșecektir (Tapscott, 2009, s. 109).

Kitabın hem yazımı uzun sürelidir hem de okunması bir haber metnine göre daha uzundur. Böylece bir kitabın derinliğini bir haber metni karşılayamamaktadır. Haber mecralarında bir birinden ilgisiz haberler peş peşe akarlar ancak bir kitap yüz yıllık, bin yıllık bir kesiti belli bakış açısıyla sunmaktadır. Kitaplardaki uzun soluklu içerik bizim haber mecralarında cevabını aradığımız "aslında şu anda ne oluyor?" sorusunun esaslı cevaplarını temin etmektedir. Şimdinin adını anmadan, geçmişte yaşanan olaylar üzerinden şimdiye ışık tutmaktadırlar (Castano ve Kidd, 2013, s. 378).

Yazının dijitalleşme ile birlikte yaşadığı rezonanslardan birisi de içeriğin seyrelmesi, yüzeyselleşmesidir. Bu esasen iki yönlü bir süreçtir. Okur ya da kullanıcılar daha kolay içeriklere ilgi göstermektedir ve öte yandan kolay tüketilen içerik daha fazla içerik tüketilmesi anlamına geleceği için internet ortamında daha fazla kullanım ve reklam alanı anlamına gelecektir. Bu karşılıklı ilişki içeriğin kalitesinin azalması anlamına gelmektedir. Çünkü günlük sorunlar günlük ve hatta anlık haber mecralarında sunuldukları biçimde ele alındıklarında çözülemezler çünkü bir şekilde başka bir sorunun, daha büyük bir sorular kümesinin alt kümesidir. Bu sebeple kitapların perspektif sağlayan, derinlemesine düşünmeye sevk eden, bir sorun üzerinde belli bir süre odaklanmayı sağlayan doğası olmaksızın insan zekası dijital dünyanın bulanık akışında patinaj yapacaktır (Holiday, 2018a). İnternet, yayıncılığı kökünden değiştirmiştir. Washington Post internette günde 12 makale yayınlayacak içerik üreticisi talep etmektedir. Günün her saati ve haftanın her günü içerik yenilenmek, üretilmek ve tüketime sunulmak zorundadır. Bu bir ticari rekabet ve zorunluluk sonucudur. İnternet yayıncılarının yayın yapmak için sonsuz bir alanı varken yayınlayabilecekleri içeriklerin ise sınırı yoktur. Her zamankinden daha fazla haber, daha fazla yorum, video, grafik, fotoğraf insanları ayartmakta ve dikkatlerini sömürmektedir. Akan içerik insanları kendilerine yetişmeye çağırmakta ve sonucunda yetersizlik hissi ile vazgeçilmesine neden olmakta, geriye dağınık bir algı bırakmaktadır.

Haber siteleri, haber yazan profesyoneller bir defa bir konu hakkında ilgi gösterdikten sonra her gün o konu ile ilgili yeni hikayeler bulup yazmaktadır. İnsanların ilgisi azalıp haber yazmak için harcanan zaman ve iş gücüne değecek değeri karşılamayana kadar bu devam etmektedir. Bu durum okurlar, haber tüketicileri için sağlıksız "tüketim"dir. Gerekli olduğu tartışmalı pek çok içerik hikaye edilmek, hikayeyi güncellemek için kullanılmaktadır. Anlık üretilen, hemen tüketilmek için üretilen içeriğin kalıcı olması, uzun vadeli bir donanım sağlaması imkansızdır. Bu türden içerikler yüzeysel olmak zorundadır. Derinlemesine bilgi vermesi planlanan içerik karlı olmayacağı gibi sırada bekleyen okunacak onca içerik varken kimse ne olduğunu anlamaya zahmet etmeyecektir. $\mathrm{Bu}$ çerçeveden bakıldığında insan zihni kalitesiz içerik tarafından dolmakta ve zamanla şekillenmektedir.

Devamlı bir dikkat dağınıklığı ve bölünme içinde insanlar için felsefi derinliğin, tarihsel bakış açısının, olayların arka planının, sosyolojik ve kültürel gerçekliklerin pek bir anlamı kalmamaktadır. Özellikle de her dakika bölünmeye ve bildirim almaya alışmış günümüz insanı için bu gerçeklik daha yakıcı bir boyuta ulaşmıștır. Günümüz insanı dikkatinin dağıtılması, bölünmesi ve daha çok vakit geçirmesi için dizayn edilmiş sosyal ağların, 
haber kanallarının tam anlamıyla kuşatması altına girmiștir ve her an ilgisi sömürülmekte ve daha fazlası için kışkırtılmaktadır (Holiday, 2018b).

\section{Sonuç ve Değerlendirme}

Kemikler üzerine atılan çiziklerle başlayan yazının tarihi kil tabletlere, ideogramlara, hiyerogliflere, genetik alfabeye, matbaaya ve dijital iletişim araçlarına kadar, hem farklı biçimler almış hem de farklı ortamlarda sunulmuştur. Yazı, sözlü bir ifadenin ifadesidir; temeli sese dayanır (Ong, 2007). Dolayısıyla sesin aldığı her biçim onun taşıdığı anlamı aktarabilme kapasitesine olumlu ya da olumsuz etkide bulunmuştur. Öte yandan yazının taşındığı her bir ortam da yazının hem anlamı içerme ve aktarma kapasitesine etki etmiş hem de insanın duyumsamasında değişim meydana getirmiştir. Sözün doğası yüz yüzeliği gerekli kılmaktadır; yer ve zaman birlikteliği söz konusudur; karşılıklı duyguları diğer iletişim biçimlerinden daha fazla içerir; kulağın egemenliğindeki bir duyumsal evren söz konusudur. Tonlamalar, sözün tınısı, içeriğin yoğunluğu kendisine hastır. Yazının ortaya çıkması ile yazılı kültürün ortaya çıkması arasında zamansal olarak önemli fark vardır. Yazı M.Ö. 4000'lerde ortaya çıkmış ancak yazılı kültür matbaanın icadıyla gerçekleşen bir sürecin adıdır. Bu bağlamda yazının icadı değil yaygın kullanımı temel alınmaktadır. Yazının etkisinin geniş kitlelerce hissedilmesi ve gözün duyumsamasında, rasyonel ve analitik bir akıl etme biçiminin oluşması 15. Yüzyılda olmuştur. Yazının taşıyıcılığını yaptığı egemen düşünsel ve bilişsel süreçler bugün için erozyona uğramakta, yerine başka bir kültür ortamı inşa edilmekte, örülmektedir. Bu ortamda yazı, taşıdığı metaforlarla, içeriğin yoğunluğu ve kalitesiyle, aynı ortamda yer aldığı diğer görüntü, ses gibi iletişim unsurlarıyla birlikte duyumsanmasıyla rezonans olușturmuştur.

Dijital iletişim ortamında mesajın gücü anlık oluşundadır. Yazı üretilir ve anında dolașıma sokulur. İçerik olarak gücü zayıflamış, tutarlılığı erozyona uğramıștır. Ömrü ise üzerine gelecek olan diğer bir haberle, mesajla son bulacaktır. Gerektiğinde arşivde hemen ulaşılmak üzere beklemektedir anca zaman akışına giderek gerilere, diplere doğru gidecektir. Dijital oramda akış son derece yoğun ve hızlıdır. Yoğunluk içeriğin niceliğinden kaynaklanmaktadır. Nitelik net biçimde seyrelmiş, içerik yüzeyselleșmiştir. $\mathrm{Bu}$ yüzeyselleșmenin iki yüzü bulunmaktadır. Birincisi yeni ortamın talebi içeriğin sürekli güncellenmesidir. Gelen her bir yeni içerikte okumanın ve içeriğin kalitesi doğal olarak düşmekte, anlatılana odaklanma daha az mümkün olmaktadır. Bu okurun ya da kullanıcının motivasyonuyla ilgilidir. İkincisi ise dijital içerik üreticilerinin derin okuma yapacak içeriği sağlama becerisi zamansal olarak kısıtlanmış bulunmaktadır. Günlük, bir yazarın yapabileceğinden çok daha fazlası yazılmakta ve hızlı bir editörlük sürecinden geçtikten sonra yayınlanmaktadır. Buna ek olarak her bir tıklamanın reklam gelirine dönüștüğünü düşünecek olursak ilgi çeken konularda gerekli olmayan içeriklerde yer almaktadır.

Dijital iletişim ortamlarında kullanıcılar hem okur hem de yazardır. İçerik hızlı biçimde kopyalanıp çoğaltılmakta değiştirilmekte ve aslında kimliksizleşmektedir. Matbaanın getirisi olan yazarlık kurumu ve telif hakları ortadan kalkmaya başlamıştır. İnsanlar bir araya gelerek müşterek metinler oluşturmaktadır. Metinler arasına yerleștirilen linkler sayesinde bitmeyen ve yatay olarak seyir eden okumalar yapmaktadır. Yazı ile birlikte video, ses ve diğer görsel içerik de metinde yer almaktadır. Okurun yorum gücü parçalanmaktadır ve hatta işlevsizleștirilmektedir. İçerik hazır, çiğnenmiş biçimde sunulmaktadır. 
Yazı sözü mekana bağlamış ve zaman içinde kalıcı kılmıştır. Söz tümden gelimci bir mantıkla yeniden düzenlenmiş, analitik, düzenli ve tutarlı bir biçime kavuşmuştur. Dijital ortamlarda söz yeniden rezonansa uğramış, dijital ortamın koşullarında yeni bağlama kavuşmuştur. Burada söz almış olduğu yeni biçimle metin kopuk, parçalı ve bütünlükten yoksundur. Analitik kabiliyeti azalmış, neden sonuç ilişkisi aramayan, yorgun ve dalgın bilinçler üretilmektedir. Sanders'in (2012, s. 128) de dediği gibi okumayı radikal biçimde yeniden tanımlamalı ve bunu yaparken de yeni bağlamlar üreten ortamlar hakkında esaslı sorular sormalıyı.

\section{Kaynakça}

Asutay, H. (2009). Elektronik yazın, yeni teknolojilerle birlikte yazın dünyasında ortaya çıkan yeni yazınsal tür ve biçimler. Trakya Üniversitesi Sosyal Bilimler Dergisi, 11 (2), 63-86 içinde. Erişim Adresi: https://dergipark.org.tr/tr/download/article-file/321630

Berthof, A. E. (1998). Önsöz. Freire, P. ve Macedo, D. Okuryazarlık, Sözcükleri ve Dünyayı Okuma (s. 17-32) içinde. (Serap Ayhan, Çev.). Ankara: İmge Kitabevi.

Binark, M. (2014). Giriş. Mutlu Binark (Ed.). Yeni Medya Çalışmalarında Araştırma Yöntem ve Teknikleri, (s. 15-25) içinde. İstanbul: Ayrıntı Yayınevi.

Carr, N. (2012). Yüzeysellik: İnternet Bizi Aptal Mı Yapıyor? (İbrahim Kapaklıkaya, Çev.). İstanbul: Ufuk Yayınları.

Castano, E. ve Kidd, D. C. (2013). Reading Literary Fiction Improves Theory of Mind. Sience, 342, 377-380.

Castells, Manuel. (2016). İletişimin Gücü. (Ebru Kılıç, Çev.) İstanbul: Bilgi Yayınevi.

Chartier, Roger. (1997). Yeniden Geçmiş Tarih, Yazılı Kültür, Toplum. (Levent Arslan, Çev.) Ankara: Dost Kitapevi.

Çomu, T. ve Halaiqa, İ. (2014). Web İçeriklerinin Metin Temelli Çözümlenmesi. Yeni Medya Çalışmalarında Araştırma Yöntem ve Teknikleri, (s. 26-87) içinde. Mutlu Binark (Ed.). İstanbul: Ayrıntı Yayınevi.

Dursun, Ç. (2013). Sözlü, Yazllı ve Görsel Kültürde İnsan ve Toplum. İletişim Sosyolojisi, Hayati Tüfekçioğlu, (Ed.). T.C. Anadolu Üniversitesi Yayını. 2666. Açıköğretim Fakültesi Yayını No: 1632. Anadolu Üniversitesi.

Eagleman, D. (2016). Beyin, Senin Hikayen. (Zeynep Arık Tozar, Çev.). İstanbul: Domingo.

Freire, P. ve Macedo, D. (1998). Okuryazarlık, Sözcükleri ve Dünyayı Okumak, (Serap Aydın, Çev.). Ankara: İmge Yayınevi.

Gitelman, L. (2006). Always Already New: Media, History and the Data of Culture. Cambridge MA: MIT Press.

Goody, J. (2011). Yaban Aklın Evcilleştirilmesi. (Koray Değirmenci, Çev.). İstanbul: Pinhan Yayıncilık.

Goody, J. (2013). Yazılı ve Sözel Arasındaki Etkileşim. (Osman Bulut, Çev.). İstanbul: Pinhan Yayıncilık.

Hill, K. (2014, Temmuz). Ex-Facebook Data Scientist: Every Facebook User Is Part Of An Experiment At Some Point. Erişim. 28.08.2018. https://www.forbes.com/sites/ kashmirhill/2014/07/07/ex-facebook-data-scientist-every-facebook-user-ispart-of-an-experiment-at-some-point/\#29358ba538e5 
Holiday, R. (2018)a. Why Everyone Should Watch Less News. Erişim: 24.08. 2018. https:// medium.com/s/story/the-case-for-watching-less-news-8020c88fd5f.

Holiday, R. (2018)b. If You Watch “THE NEWS”... I Have Some Bad News For Your Success \& Happiness. Erişim: 26.08.2018 https://medium.com/@RyanHoliday/if-you-watchthe-news-i-have-some-bad-news-for-your-success-happiness-d16a8e011ecb.

Jean, G. (2015). Yazı, İnsanlığın Belleği. (Nami Beşer, Çev.). İstanbul: YKY.

Köroğlu, O. (2012). İnsan Bilgisayar Etkileșimleri Açısından Yeni İletișim Ortamları, AJIT- e: Online Academic Journal of Information Technology, 2012-3(6), DOI: 10.5824/13091581.2012.1.001.x.

Maigret, E. (2016). Medya ve İletişim Sosyolojisi. (Halime Yücel, Çev.). İstanbul: İletişim Yayınları.

Manguel, A. (2013). Okumanın Tarihi. (Fosun Elioğlu, Çev.). İstanbul: YKY.

McLuhan, M. (1996). Understanding Media, Extantion of Man. Cambridge, Massachusetts: First MIT Press Edition.

McLuhan, M. (2001). Gutenberg Galaksisi, Tipografik İnsanın Oluşumu. (Gül Çağalı Güven, Çev.). İstanbul: YKY.

Postman, N. (2012). Televizyon: Öldüren Eğlence, Gösteri Çağında Kamusal Söylem. (Osman Akınhay, Çev.). İstanbul: Ayrıntı Yayınevi.

Ong, W. J. (2007). Sözlü ve Yazılı Kültür, Sözün Teknolojileşmesi. (Sema Postacıŏlu Banon, Çev.). İstanbul: Metis.

Paine, T. (2018). Akıl Çağı. (Ali İhsan Dalgıç, Çev.). İstanbul: İş Bankası Yayınları.

Ramashandran, V. S. (2011). Öykücü Beyin. (Ayşe Cankız Çevik, Çev.). İstanbul: Alfa Yayınları.

Robinson, A. (2014). Yazının Kökenleri. David Crowley-Paul Heyer (Ed.). İletişim Tarihi. (Berkay Ersöz, Çev.). (S. 66-75) İçinde. Ankara: Siyasal Yayınevi.

Rowland, D. W. (2014). Giriş. İletişim Tarihi, David Crowley-Paul Heyer (Ed.). İletişim Tarihi. (Berkay Ersöz, Çev.). (S. 10-22). Ankara: Siyasal Yayınevi.

Sanders, B. (2012). Öküzün A’sl, Elektronik Çağda Yazılı Kültürün Çöküşü ve Şiddetin Yükselişi. Çev. (Şehnaz Tahir, Çev.). İstanbul: Ayrıntı Yayınevi.

Sweller, J. (1999). Instructional Design in Technical Areas. Camberwell, Australia: Austrailan Council for Educational Research (ACER).

Topscott, D. (2009). Grown Up Digital. New York: McGraw-Hill.

Van Dijk, J. (2018). Ağ Toplumu. (Özlem Sakin, Çev.). İstanbul: Kafka Epsilon Yayıncılık. 


\title{
Digital Resonance of Writing and Becoming Superficial of the Content
}

\author{
Rıdvan Yücel (Lect. Ph.D.)
}

\section{Extended Abstract}

The quality of communication factors has gone through changes throughout history due to the changes in technologies of means of communications. Communication is still changing today thanks to computers and Internet. Writing as the most important communication component of history of humanity is going through both qualitative and quantitative changes. Computers and Internet have speeded up the production and consumption processes of the content, and thus the content of writing became thinner while density of knowledge is reduced. The environments in which writing is read and multimedia technologies have caused reduction in the power of expression. Advertisements and the concern to be read led to the production of content which does not push the intellectual limits of readers. Concerned with being seen and wanting to stand out in the crowd, content generators were led to direct the reader's attention to many factors apart from writing using other communication tools such as video, graphics etc. The ease in generation and distribution of writing and the reduction in publishing costs with new communication technologies brought with them the issues of labor and quality in the process of preparing texts for publication. Writing looks like it had acquired a new form and content today with the dominance of digital communication tools. In this study, it is assumed that the writing forms according to the medium and certain opportunities and limits. The opportunities and limits of the writing form the discourse of the writing. In this context, in this study, it is aimed to reveal the characteristics of writing that change according to the media. The changing discourse of writing and its features in written and digital media have been tried to be revealed by literature review and by examining the basic and current works on the subject.

The written text has been in existence in various ways and forms since its inception. The first books were spoken texts written for the public. Later, with the emergence and spread of codex, individual reading became widespread and the contents of the texts in the books did also change. With the emergence of the printing press, a real information explosion has been experienced, communication and access to information have gained great importance and the content of the writing has been diversified. Until the printing press appeared, the books covered religious issues or recorded opinions and suggestions about state administration. Together with the printing press, articles on daily subjects and lifestyles have become widespread. Novels, newspapers and magazines have led to a significant transformation. Trade and economy, scientific developments, numerical data and statistics have become the basic elements of the written texts. Nowadays, internet carries the content of the text to another dimension. The faster the flowing information, the less dense the content appears to be. The number of information that the individual encounters daily has increased but the weight of the information has decreased.

The main dynamics that determine the content of the article are the decrease in the cost of the media, the increase in the literacy rate and the spread of communication tools. The increased amount of information and the new features of the media that are increased by digitalization also affect the way that written text is read and understood. Making an 
individual reading in an isolated place formed by a printing house has taken the form of reading at anytime and anywhere with digitalization. The text was introduced to multimedia technology in a digital environment. The linear reading habit of the book has been transformed into horizontal reading with digitalization. Articles produced by multiple and anonymous authors have emerged. Thus, endless, infinite, non-focal or weak focal points of reading behavior emerged. In an environment of intense competition, publishers feel compelled to constantly support their pages with new content in order to capture readers.

Human perception is stuck in narrow time intervals on bright screens where notifications rain. Making long readings and the in-depth focus on the behavior of the book world became a model of the classical reading methodology. The skills that come to the forefront with digitalization are to reach the information, to know the ways and opportunities to access it, to distinguish between the right information and the wrong information, to be able to diagnose the bias and freedom of information correctly. The transfer of the text from the printed media to the digital media has transformed the content and quality of the text and this transformation took place in the form of superficialization. In this article, this transformation is evaluated as a resonance.

In this context, the existing dynamics of writing do not disappear when the environment changes, but change is experienced. According to the environment in which the writing takes place, the possibility and limits of the discourse power of the writing have been evaluated. With the literature review, the subject was dealt with and it was concluded that the power and depth of the writing was in its simplicity.

Keywords: Reading, Written culture, Digital culture, Resonance, Superficiality. 